\title{
Durability of Lightweight Concrete Using Oil Palm Shell as Aggregates
}

\section{Yasmine Binta Traore ${ }^{1,2 *}$, Adamah Messan2 ${ }^{2}$, Kinda Hannawi ${ }^{3}$, Jean Gerard ${ }^{4}$, William Prince ${ }^{3}$, François Tsobnang²}

${ }^{1}$ Université de Fada N'Gourma/Ecole Supérieure d'Ingénierie (ESI), Fada N’Gourma, Burkina Faso

${ }^{2}$ Institut International d'Ingénierie de l'Eau et de l'Environnement (2iE), Laboratoire Eco-Matériaux et Habitats Durables (LEMHaD), Ouagadougou, Burkina Faso

${ }^{3}$ Institut National des Sciences Appliquées de Rennes (INSA-Rennes), Laboratoire de Génie Civil et de Génie Mécanique (LGCGM), Rennes, France

${ }^{4}$ Centre de Coopération International en Recherche Agronomique pour le Développement (CIRAD), Unité de recherche Biomass, Wood, Energy, and Bioproducts (BioWooEB), Montpellier, France

Email: *yasmineb.traore@gmail.com

How to cite this paper: Traore, Y.B., Messan, A., Hannawi, K., Gerard, J., Prince, W. and Tsobnang, F. (2021) Durability of Lightweight Concrete Using Oil Palm Shell as Aggregates. Open Journal of Civil Engineering, 11, 1-13.

https://doi.org/10.4236/ojce.2021.111001

Received: December 8, 2020

Accepted: January 26, 2021

Published: January 29, 2021

Copyright (c) 2021 by author(s) and Scientific Research Publishing Inc. This work is licensed under the Creative Commons Attribution International License (CC BY 4.0).

http://creativecommons.org/licenses/by/4.0/

\begin{abstract}
Oil Palm Shell (OPS) concrete can be used in different fields of construction. To determine more accurately the fields of application, it is important to know and understand the behaviour of OPS concrete over the long term and when it is in aggressive environments. This paper presents the results of studies conducted on the durability of OPS concrete. Water absorption capacity, electrical resistivity and apparent diffusion of chloride ions have been measured on different concrete samples. In addition, the behaviour of OPS concretes to carbonation was studied in an environment rich in carbon dioxide. Results show that OPS concrete has an absorptivity of $0.97 \mathrm{~kg} / \mathrm{m}^{2} \cdot \mathrm{h}^{1 / 2}$, an electrical resistivity of $64.37 \Omega \cdot \mathrm{m}$ and an apparent diffusion coefficient of chloride ions of $3.84 \times 10^{-12} \mathrm{~m}^{2} / \mathrm{s}$ after 90 days. All these results of OPS concrete are very close to those of concrete with normal aggregate and other lightweight concrete, which mean OPS concretes have globally good properties with regard to durability.
\end{abstract}

\section{Keywords}

Oil Palm Shell, Lightweight Concrete, Durability, Carbonation

\section{Introduction}

The use of oil palm shells (OPS) as aggregates in concrete is an interesting alternative to reduce the negative impact of the concrete industry. During the last 
two decades, authors have shown the potential use of OPS to produce lightweight structural concrete [1] [2] [3]. Concrete using OPS as aggregate has a density range from 1725 to $2050 \mathrm{~kg} / \mathrm{m}^{3}$ which corresponds to a $15 \%-25 \%$ reduction compared to the density of ordinary concrete [1]. This reduction leads to a reduction of dead loads in the structure, and consequently to a reduction of the construction costs [4]. However, the mechanical properties of concrete decrease with increasing OPS content [5] [6]. This decrease in the performance of OPS concrete is attributed to the intrinsic properties of OPS. These natural aggregates are highly porous, have a high-water absorption capacity and have poor adhesion with the cement matrix. Taking into account these shortcomings and in order to improve the final properties of concrete, a previous article dealt with the influence of different OPS treatments on the physical and mechanical properties of concrete [7].

OPS concrete can be used as structural concrete, for the construction of load-bearing or filling walls. They are expected to last over time, requiring little or no maintenance. To ensure this and encourage the use of OPS concrete on a larger scale, it is important to determine its behaviour over the long term in relation with the environment in which it is exposed. Very few studies have focused on the long-term behaviour of OPS concrete. In this study, the durability of the OPS concrete was then evaluated with regard to a wet environment through classic durability indicators such as water absorption capacity, electrical resistivity and apparent diffusion of chloride ions. In addition, a carbonation test in a controlled atmosphere made it possible to study concrete in an environment polluted with carbon dioxide.

\section{Experimental Methods and Materials}

\subsection{Materials Used}

The cement used is a CEM I 42.5 from the company CIMTOGO produced according to EN 197-1. OPS come from an industrial production site of palm oil. Before any treatment and/or utilisation, the OPS is washed in water to eliminate soil and grease residues then dried in the open air. They are then sieved: only the particles with a diameter less than $8 \mathrm{~mm}$ are retained. The behaviour of OPS concrete has been compared to an ordinary granite-based aggregate concrete. The gravel and sand used to manufacture concrete, come from a local river in Burkina Faso.

\subsection{Properties of the Materials Used}

The cement used has a specific density, a bulk density and a BET surface area of $3150 \mathrm{~kg} / \mathrm{m}^{3}, 1060 \mathrm{~kg} / \mathrm{m}^{3}$ and $2.96 \mathrm{~m}^{2} / \mathrm{g}$ respectively. OPS's relative density is 1340 $\mathrm{kg} / \mathrm{m}^{3}$, its bulk density is $560 \mathrm{~kg} / \mathrm{m}^{3}$ and 24 -hour water absorption capacity is $23.3 \%$. The sand used has a density of $2680 \mathrm{~kg} / \mathrm{m}^{3}$. Its bulk density is $1530 \mathrm{~kg} / \mathrm{m}^{3}$ and its Fineness modulus is 2.90 . The gravel used is in the same range: density of 
$2660 \mathrm{~kg} / \mathrm{m}^{3}$ and a bulk density of $1510 \mathrm{~kg} / \mathrm{m}^{3}[8]$.

\subsection{Preparation of Concrete}

Concrete have been manufactured according to the same procedure as for Traore et al. [9]. Three concrete mixes were made by replacing $0 \%(0 \mathrm{~N}), 50 \%$ $(50 \mathrm{~N})$ and $100 \%$ of normal aggregate by OPS. The formulation was done considering a volume substitution of the coarse aggregate by OPS. The concrete tested are composed of $550 \mathrm{~kg} / \mathrm{m}^{3}$ of cement for a W/C ratio of 0.4 . The sand to cement and OPS to cement ratios were 1.66 and 0.6 , respectively. The workability of the concrete was kept constant for all the formulations, using a high water-reducing superplasticizer. The concrete is poured and vibrated in 3 layers in each mould. Demoulding is carried out after 24 hours and the specimens are stored into water for 28 days.

It is well known that the durability of concrete is highly dependent on the structure of its pores. The main parameters we will use to evaluate the durability of concrete will therefore be related to its permeability and the transport of liquids and gases within it. We have evaluated certain durability factors such as water absorption by capillarity, diffusion of chloride ions, and carbonation.

\subsection{Experimental Investigations}

\subsubsection{Capillary Absorption}

To evaluate capillary absorption, concrete samples are placed in contact with water (Figure 1). This method consists in measuring the increase in mass of a sample resulting from water absorption as a function of time, when only one surface of the sample is exposed to water according to the prescriptions of the AFPC-AFREM [10]. The mass of absorbed water is determined by successive weighing of the samples at several intervals. The timeframes used are $0.25,0.5,1$, $2,4,8$ and 24 hours. At each interval, the specimens are removed from the water, wiped with a damp sponge, weighed and placed back in the container.

Capillary absorption coefficient in $\mathrm{kg} / \mathrm{m}^{2}$ is defined by the following relationship (Equation (1)):

$$
C_{a}=\frac{M_{x}-M_{0}}{A}
$$

$M_{x}$ : Mass of specimen measured at maturity $x(\mathrm{~kg})$;

$M_{0}$ : Initial dry mass of the sample $(\mathrm{kg})$;

$A$ : Section of immersed sample $\left(\mathrm{m}^{2}\right)$.

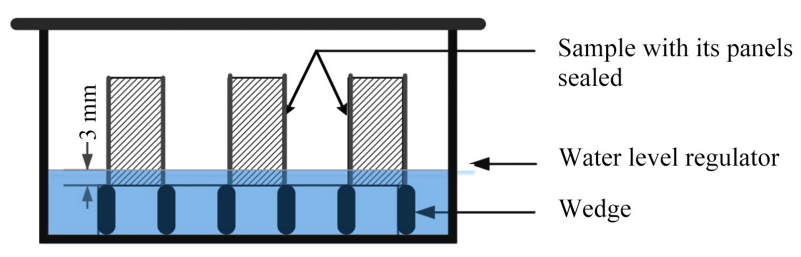

Figure 1. Device for measuring capillary absorption. 


\subsubsection{Electrical Resistivity}

Another indicator of the durability of concrete is electrical resistivity. It describes the ability of a material to resist the passage of an electric current [10]. It can be used to assess the risk of corrosion of a concrete structure. The electrical resistivity of different concretes was measured along the longitudinal axis of cylindrical specimens $40 \mathrm{~mm}$ in diameter and $60 \mathrm{~mm}$ long. The test is carried out according to the procedure described by Spragg et al. [11]. Two electrodes are placed at the ends of a specimen and two wet sponges are inserted between the contact faces. The electrodes are connected to a power supply, which flows through the specimen (see device in Figure 2.) The apparent electrical resistivity $\rho$ is given by the following Equation (2):

$$
\rho=\frac{U}{I} \times \frac{S}{L}
$$

$\rho$ : apparent electrical resistivity of the specimen in $\Omega \cdot \mathrm{m}$;

$U$ : electrical voltage measured in $\mathrm{V}$;

I: current intensity measured in $\mathrm{mA}$;

$S:$ cross-section of the specimen in $\mathrm{mm}^{2}$;

$L$ : length of the specimen in $\mathrm{mm}$; the length of the specimen in $\mathrm{mm}$.

\subsubsection{Diffusion of Chloride Ions}

In an aggressive environment, when one side of the concrete is in contact with a solution possibly containing chloride ions, it is absorbed into the pore structure by capillary suction [9]. In general, capillary absorption alone does not usually carry the chloride ions down to the reinforcement to corrode it. Chloride ions can also move by diffusion, due to a concentration gradient.

In this study, test tubes were placed $20 \mathrm{~cm}$ long in contact with a sodium chloride $(\mathrm{NaCl})$ solution (measured at $0.5 \mathrm{M})+\mathrm{a} \mathrm{NaOH}$ saturation solution (measured at $0.1 \mathrm{M}$ ). At different periods (30, 60 and 90 days) the specimens were split, and the depth of penetration of the chloride ions was measured after spraying with a silver nitrate solution $\left(\mathrm{AgNO}_{3}\right)$. From these penetration depths, an apparent diffusion coefficient can be calculated according to Equation (3) proposed by Baroghel-Bouny et al. [10].

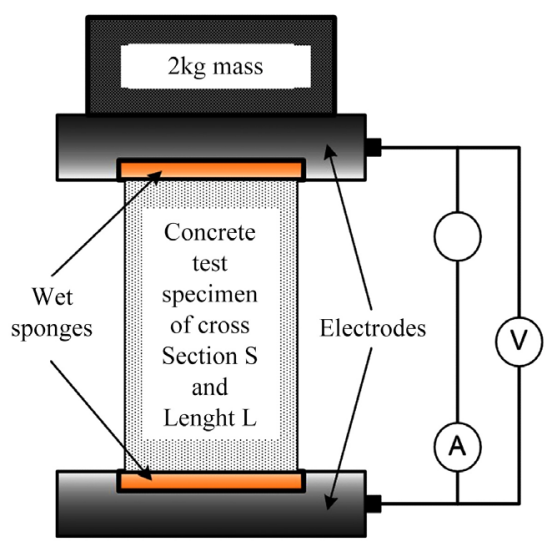

Figure 2. Device for measuring electrical resistivity. 


$$
D_{\text {app }}=\frac{X_{d}^{2}}{4 t}
$$

$D_{a p p}$ : The apparent diffusion coefficient of chloride ions in saturated condition $\left(\mathrm{m}^{2} / \mathrm{s}\right)$;

$X_{d}$ : Penetration depth of chloride ions (m);

$t$. Immersion time in the salt solution (s).

It is important to note that this method is simple but has some drawbacks. It is difficult to measure the depth of ion penetration accurately. We have then used the average value of 3 depths.

\subsubsection{Carbonation Test}

In conditions with a concentration gradient of carbon dioxide, $\mathrm{CO}_{2}$ diffuses through the pores of concrete. It dissolves into carbonic acid $\left(\mathrm{H}_{2} \mathrm{CO}_{3}\right)$. The result of this is a decrease of $\mathrm{pH}$ and the formation of calcium carbonate $\mathrm{CaCO}_{3}$, which tends to fill the pores of concrete and slow down the phenomenon. Carbonation is therefore not dangerous for unreinforced concrete. But, in the case of reinforced concrete, when the carbonated zone reaches the reinforcements, they are depassivated and susceptible to corrosion. Hence, it's important to assess the sensitivity of OPS concrete to carbonation. This sensitivity was measured by an accelerated carbonation test with $\mathrm{CO}_{2}$. Concrete samples are placed into a chamber with controlled temperature and humidity, and a high concentration of $\mathrm{CO}_{2}$. Test specimens are split at the end of the test period and a phenolphthalein solution is sprayed on the split sides. Phenolphthalein is a coloured indicator that reveals areas with a $\mathrm{pH}$ above 9. The healthy core of the test specimen turns purplish pink and the carbonated area remains colourless.

\section{Results and Discussion}

\subsection{Capillary Absorption}

The results of the capillary absorption test performed according to the AFREM procedure are presented in Figure 3. It shows the influence of the rate of substitution by OPS on the water absorption kinetics of concrete as a function of the square root of time.

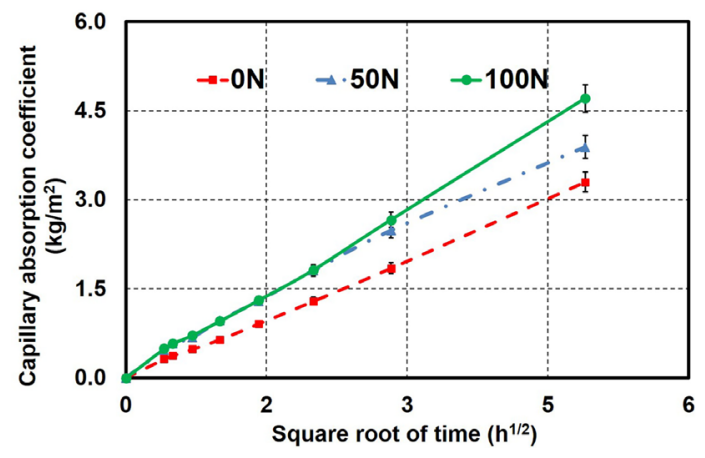

Figure 3. $24 \mathrm{~h}$ absorption kinetic of tested concrete. 
According to Balayssac et al. [12], two parameters can be deduced from the kinetic of absorption of the samples. The first part of the curves (from 0 to 1 hour) which corresponds to the initial absorption represents the filling of the largest pores, and the second part represents the filling of the finest pores.

When looking at the first part of the curves (Figure 4), it can be seen that the initial absorption is greater for concrete containing OPS. It can therefore be assumed that OPS concrete has larger pores than regular aggregate concrete. This could be explained by the poor bond between the OPS and the cement matrix, which creates larger pores at the interface. It can also be seen in Figure 4 that the initial absorption is almost identical for all concretes containing OPS (50N and $100 \mathrm{~N}$ concrete). However, in the second part of the curve (Figure 5), the slopes called absorptivity increase with the rate of substitution by OPS. Absorptivity varies from $0.68 \mathrm{~kg} / \mathrm{m}^{2} \cdot \mathrm{h}^{1 / 2}$ for concrete $0 \mathrm{~N}$ to $0.75 \mathrm{~kg} / \mathrm{m}^{2} \cdot \mathrm{h}^{1 / 2}$ et $0.97 \mathrm{~kg} / \mathrm{m}^{2} \cdot \mathrm{h}^{1 / 2}$ for $50 \mathrm{~N}$ and $100 \mathrm{~N}$ respectively. Absorptivity corresponds to the filling of the finest pores. These results are related to the porosity of concrete, $100 \mathrm{~N}$ concrete having a higher porosity than the $50 \mathrm{~N}$ and $0 \mathrm{~N}$.

\subsection{Electrical Resistivity}

Interstitial solution of concrete is very rich with various ions $\left(\mathrm{K}^{+}, \mathrm{Na}^{+}, \mathrm{Ca}^{2+} \ldots\right)$ [13]. Thus, most of the electrical conductivity occurs through this fluid present in the pores. Therefore, the more porous a concrete is, the more interstitial fluid it contains and the lower its electrical resistivity should be. OPS concrete which has higher porosity than normal concrete is expected to have a lower resistivity. However, the results mentioned in Table 1 are different. Concrete containing OPS $(50 \mathrm{~N}$ and $100 \mathrm{~N})$ have higher electrical resistivity than regular concrete $(0 \mathrm{~N})$. This can be justified by the lower electrical conductivity of OPS compared to granitic aggregates, which inhibits the conduction of electrical current.

It can also be noted that $50 \mathrm{~N}$ and $100 \mathrm{~N}$ concrete have similar values of electrical resistivity, while $100 \mathrm{~N}$ has a higher content of OPS (low electrical conductivity) than $50 \mathrm{~N}$. As $100 \mathrm{~N}$ concrete has a higher porosity than $50 \mathrm{~N}$ concrete, one could think of a compensation between the lower electrical conductivity of the OPS and the higher electrical conductivity of the water contained in the pores of $100 \mathrm{~N}$ concrete.

From the results of the electrical resistivity, it is possible to estimate the tortuosity of the pores of a concrete. It is given by the expression of Equation (4) [14]:

$$
\tau_{e l}=\frac{\sigma_{e l}}{\varepsilon \times \sigma_{0}}
$$

$\sigma_{e l}$ et $\sigma_{0}$ correspond respectively to the electrical conductivity of the concrete and to that of the interstitial solution. Since electrical conductivity is the inverse of electrical resistivity, Equation (5) is written as follows:

$$
\tau_{e l}=\frac{\rho_{0}}{\varepsilon \times \rho_{e l}}
$$




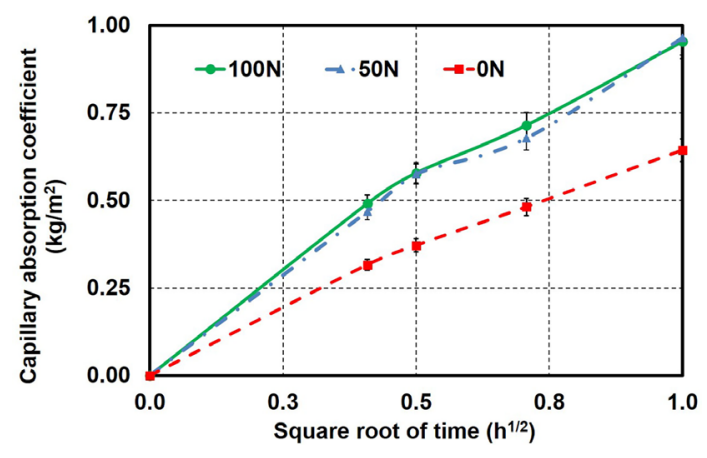

Figure 4. Initial absorption kinetic of tested concrete.

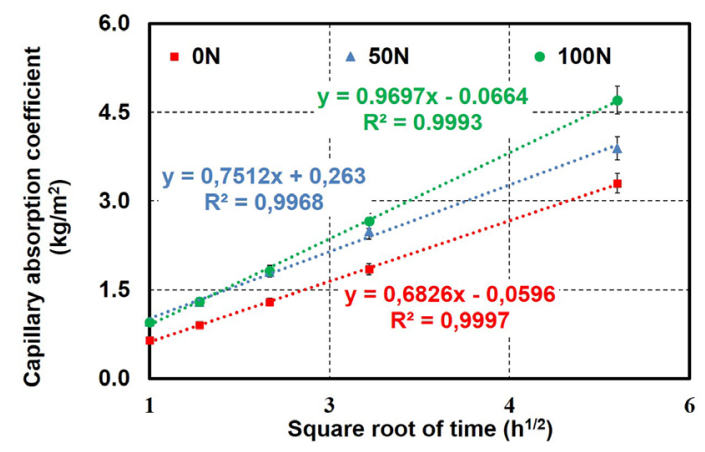

Figure 5. Absorptivity of tested concrete.

Table 1. Electrical resistivity of the tested concrete.

\begin{tabular}{cc}
\hline & Electrical resistivity $(\Omega \cdot \mathrm{m})$ \\
\hline $\mathbf{N}$ & $49.95( \pm 2.99)$ \\
$100 \mathrm{~N}$ & $64.67( \pm 4.21)$ \\
\hline
\end{tabular}

$\rho_{0}$ : Electrical resistivity of interstitial solution of the concrete $(\Omega \cdot \mathrm{m})$;

$\rho_{e \dot{i}}$ Electrical resistivity of concrete $(\Omega \cdot \mathrm{m})$;

$\varepsilon$. Porosity accessible to water.

Electrical conductivity of the interstitial solution is considered equal to 3.1 $\Omega^{-1} \cdot \mathrm{m}^{-1}$ [15]. Average values obtained for three test specimens (with a standard deviation of 0.001 ) are: $0.06,004,0.03$ respectively for $100 \mathrm{~N}, 50 \mathrm{~N}$ and $0 \mathrm{~N}$. These results mean that the more OPS content in concrete the less tortuous are its pores.

\subsection{Diffusion of Chloride Ions}

Chloride ion attack is one of the most common causes of chemical degradation of reinforced concrete [16]. Apparent diffusion coefficient of chlorides in concrete is an interesting parameter to assess its resistance to chloride penetration. The study carried out on the diffusion of chloride ions in concrete, as conducted in this research, does not claim to explain the transfer mechanisms of chloride ions in OPS concrete. Its objective is to compare the results obtained for the dif- 
ferent concretes with the normal aggregate concrete and to get an idea of the capacity of OPS concrete to resist the propagation of chloride ions.

The results on apparent diffusion coefficient of chloride ions of the tested concrete are shown in Table 2.

These results show that the apparent diffusion coefficient in concrete increases with OPS content. The diffusion coefficient of chlorides in concrete depends on the porosity of the concrete and the structure of its pores. OPS concretes have higher porosity and lower tortuosity than control concrete, which can explain the differences in the results observed.

Furthermore, it can be noted that diffusion coefficient of chloride ions over time tends to decrease for concrete containing OPS, whereas it continues to increase for the control concrete. Figure 6 gives detail of the evolution of diffusion coefficient over time. It can be supposed that a deposit of chloride ions in the pores of OPS concrete, has reduced the diffusion of the chloride ions in concrete. The same conclusion was reached by Teo et al. [9].

Studies of Teo et al. [9] give chloride diffusion coefficient varying between 6.6 $\times 10^{-12}$ and $10 \times 10^{-12} \mathrm{~m}^{2} / \mathrm{s}$ for an ordinary concrete with a W/C ratio of 0.45 , exposed to a marine environment. The results of our study show values low below those of Teo et al. and indicate a good resistance to the diffusion of chloride ions of the elaborated OPS concrete.

\subsection{Carbonation Test}

At the end of the exposure period of 90 days, phenolphthalein test was done to reveal a decrease in $\mathrm{pH}$ due to carbonation. No visible variation in colouring was observed on the elaborated concrete samples (Figure 7) which would suggest that the test specimens have not carbonated.

The carbonation process results in the consumption of portlandite $\left(\mathrm{Ca}(\mathrm{OH})_{2}\right)$ and the crystallisation of calcium carbonate $\left(\mathrm{CaCO}_{3}\right)$. The portlandite content is also a chemical indicator of durability used in several carbonation models [17] [18]. Therefore, we performed a thermogravimetric analysis (TGA) on samples taken from different parts of concrete specimen that have been exposed to carbonation (see the diagram in Figure 8): a first part named C1 located at $1.5 \mathrm{~cm}$ from the edges and a second part named C2 in the middle of the specimen

Figure 9 shows the result of TGA on $0 \mathrm{~N}, 50 \mathrm{~N}$ and $100 \mathrm{~N}$ concrete samples. They are compared to control samples that have not been exposed to Carbone dioxide.

Table 2. Apparent diffusion coefficient of chloride ions.

\begin{tabular}{ccccccc}
\hline \multirow{2}{*}{ Designation } & \multicolumn{5}{c}{ Apparent diffusion coefficient $\left(10^{-12} \mathrm{~m}^{2} / \mathrm{s}\right)$} \\
\cline { 2 - 7 } & \multicolumn{2}{c}{30 days } & \multicolumn{2}{c}{60 days } & \multicolumn{2}{c}{90 days } \\
\hline $0 \mathrm{~N}$ & 0.81 & \pm 0.08 & 1.31 & \pm 0.11 & 1.63 & \pm 0.15 \\
$50 \mathrm{~N}$ & 1.48 & \pm 0.37 & 2.20 & \pm 0.43 & 2.16 & \pm 0.13 \\
$100 \mathrm{~N}$ & 3.91 & \pm 0.44 & 3.68 & \pm 0.38 & 3.84 & \pm 0.25 \\
\hline
\end{tabular}




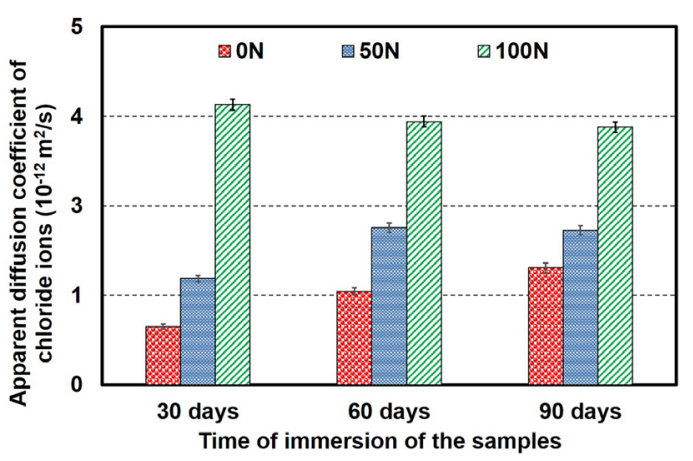

Figure 6. Evolution of diffusion coefficient of chloride ions with time.
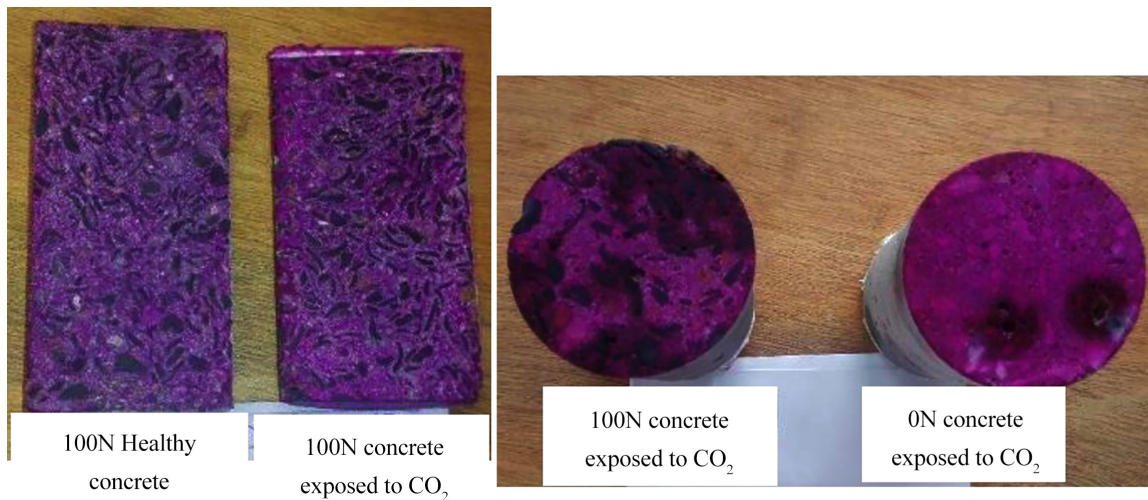

Figure 7. Phenolphthalein test result on concrete samples $0 \mathrm{~N}$ and $100 \mathrm{~N}$.

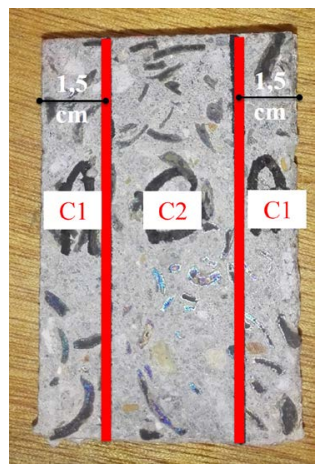

Figure 8. Diagram for taking samples from specimens for TGA.

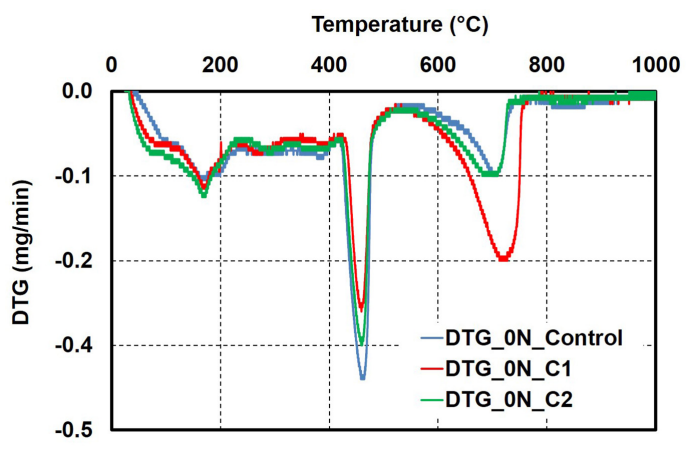



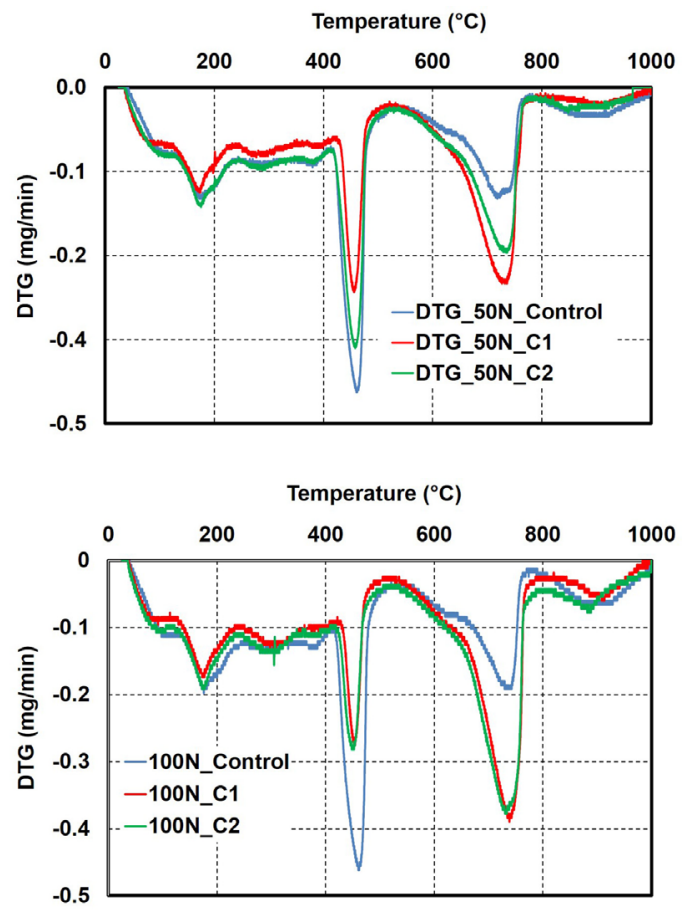

Figure 9. Diagram for taking samples from specimens for TGA.

We were interested in peaks around $450^{\circ} \mathrm{C}$ and between $800^{\circ} \mathrm{C}-900^{\circ} \mathrm{C}$ which correspond respectively to the decomposition of portlandite and calcium carbonate (especially calcite). The objective was to determine the mass rate of portlandite and calcium carbonate in the material. Based on the mass losses corresponding to these peaks, it is possible to estimate the amount of portlandite and calcite in the mixture. Portlandite $\left(\mathrm{Ca}(\mathrm{OH})_{2}\right)$ is decomposed, producing calcium oxide $(\mathrm{CaO})$ and water $\left(\mathrm{H}_{2} \mathrm{O}\right)$ which evaporates at high temperature (Equation (6)). The loss of mass observed around $450^{\circ} \mathrm{C}$ represents the evaporation of this water. By applying the principle of material conservation, the portlandite rate can be estimated (Equation (7))

$$
\begin{aligned}
\mathrm{Ca}(\mathrm{OH})_{2} & \rightarrow \mathrm{CaO}+\mathrm{H}_{2} \mathrm{O} \\
\text { Portlandite content rate }(\%) & =\frac{\Delta m_{400^{\circ} \mathrm{C}-500^{\circ} \mathrm{C}}(t)}{m_{\text {initiale }}} \frac{M_{\mathrm{Ca}(\mathrm{OH})_{2}}}{M_{\mathrm{H}_{2} \mathrm{O}}}
\end{aligned}
$$

$\Delta m\left(400^{\circ} \mathrm{C}-500^{\circ} \mathrm{C}\right):$ loss of mass of the test sample between $400^{\circ} \mathrm{C}$ and $500^{\circ} \mathrm{C}$ (mg);

$m_{\text {initial }}:$ initial mass of the sample tested $(\mathrm{mg})$;

$M_{\mathrm{A}}$ : molar mass of compound A (with $\mathrm{A}=\mathrm{Ca}(\mathrm{OH})_{2}$ or $\mathrm{H}_{2} \mathrm{O}$ ).

Applying the same principle as in the case of portlandite, the calcite content in the tested mixture can also be estimated.

The results of the analyses are compared with those of a normal sample (S), that has not been placed in the carbonation cell. The results of the monitoring of portlandite and calcium carbonate levels according to the sampling zones are shown in Figure 10 and Figure 11. 


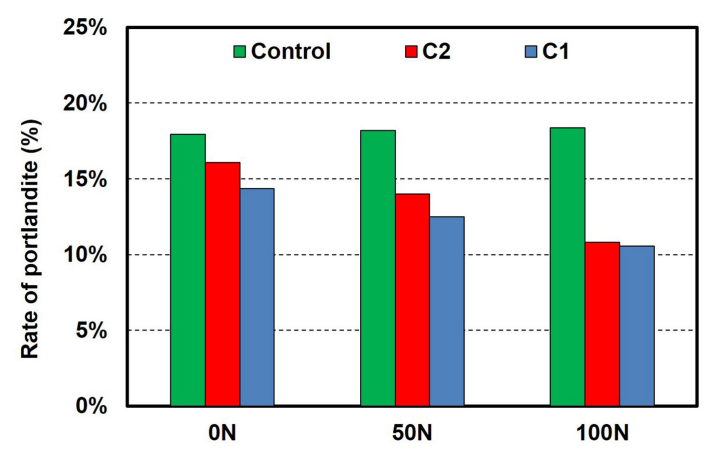

Figure 10. Mass percentage of portlandite in tested samples.

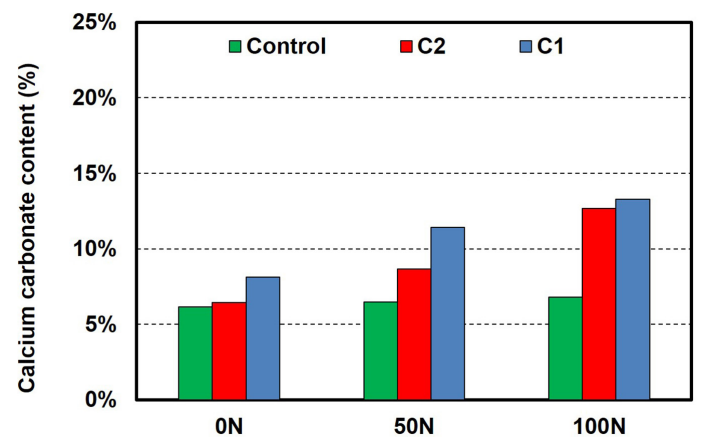

Figure 11. Mass percentage of calcium carbonate in the tested samples.

These graphs show a decrease in the portlandite content and an increase in the calcium carbonate content in zones $\mathrm{C} 1$ and $\mathrm{C} 2$ compared to normal concrete specimens (S) for all types of concrete. However, in the case of $100 \mathrm{~N}$ concrete, the portlandite content has decreased considerably to give a higher amount of calcium carbonate in both zone $\mathrm{C} 1$ and zone $\mathrm{C} 2$. These variations are less sensitive in the case of $0 \mathrm{~N}$ and $50 \mathrm{~N}$ concretes, especially in zone C2. It therefore seems that carbonation has occurred on the concrete specimens although no coloration was observed in the phenolphthalein test. $\mathrm{CO}_{2}$ has diffused into the concrete specimens and the depth of diffusion is greater as the OPS content in concrete increases. These results can be explained by the increase in porosity of the concrete as a function of the OPS content.

Phenolphthalein is a coloured indicator with a turning point around $\mathrm{pH} 9$. During the carbonation process, the dissolution of $\mathrm{CO}_{2}$ in the interstitial water causes a decrease in $\mathrm{pH}$. The portlandite then dissolves to restore the $\mathrm{pH}$. As the portlandite is used up, the $\mathrm{pH}$ of the pore solution continues to acidify. It can then be assumed that the amount of $\mathrm{Ca}(\mathrm{OH})_{2}$ in OPS concretes being important, the $\mathrm{pH}$ of the solution did not decrease significantly and remained above 9.

\section{Conclusions}

This research was carried out to study the influence of OPS on the durability of structural concrete using them as coarse aggregate. Concrete damages can be attributed to several causes. However, the most important causes are linked to 
concrete capacity to allow fluids to pass through its pore network. Although having a higher porosity accessible to water than regular concrete, OPS concretes have generally shown good properties with regard to durability.

The water absorption capacity and the diffusion of chloride ions increase in concrete with the OPS content. Nevertheless, the values obtained for OPS concretes are admissible and correspond to good quality concretes. Unlike the expected result, the use of OPS had a positive effect on the electrical resistivity, which was related to the low electrical conductivity of CNP.

Phenolphthalein test did not detect any carbonation on the concrete samples. However, a thermal analysis on different concrete profiles showed that carbon dioxide still diffused into concrete and carbonation occurred at certain points. OPS concretes (100N and $50 \mathrm{~N})$, which were more porous than ordinary concrete $(0 \mathrm{~N})$, were the most carbonated. As the phenolphthalein test was suitable for $\mathrm{pH}$ values around 9, it could be concluded that the $\mathrm{pH}$ of the tested concretes remained above this value although carbonation occurred. The decrease in $\mathrm{pH}$ being the most important in terms of carbonation and corrosion of the reinforcement, it can be said that concrete formulated with OPS has a good resistance to carbonation.

\section{Conflicts of Interest}

The authors declare no conflicts of interest regarding the publication of this paper.

\section{References}

[1] Alengaram, U.J., Muhit, B.A.A. and Jumaat, M.Z.B. (2013) Utilization of Oil Palm Kernel Shell as Lightweight Aggregate in Concrete-A Review. Construction and Building Materials, 38, 161-172. https://doi.org/10.1016/j.conbuildmat.2012.08.026

[2] Shafigh, P., Mahmud, H.B., Jumaat, M.Z. and Zargar, M. (2014) Agricultural Wastes as Aggregate in Concrete Mixtures-A Review. Construction and Building Materials, 53, 110-117. https://doi.org/10.1016/j.conbuildmat.2013.11.074

[3] Hamada, H.M., Thomas, B.S., Tayeh, B., Yahaya, F.M., Muthusamy, K. and Yang, J. (2020) Use of Oil Palm Shell as an Aggregate in Cement Concrete: A Review. Construction and Building Materials, 265, Article No. 120357. https://doi.org/10.1016/j.conbuildmat.2020.120357

[4] Olanipekun, E.A., Olusola, K.O. and Ata, O. (2006) A Comparative Study of Concrete Properties Using Coconut Shell and Palm Kernel Shell as Coarse Aggregates. Building and Environment, 41, 297-301. https://doi.org/10.1016/j.buildenv.2005.01.029

[5] Mo, K.H., Visintin, P., Alengaram, U.J. and Jumaat, M.Z. (2016) Prediction of the Structural Behaviour of Oil Palm Shell Lightweight Concrete Beams. Construction and Building Materials, 102, 722-732. https://doi.org/10.1016/j.conbuildmat.2015.10.184

[6] Mo, K.H., Chin, T.S., Alengaram, U.J. and Jumaat, M.Z. (2016) Material and Structural Properties of Waste-Oil Palm Shell Concrete Incorporating Ground Granulated Blast-Furnace Slag Reinforced with Low-Volume Steel Fibres. Journal of 
Cleaner Production, 133, 414-426. https://doi.org/10.1016/j.jclepro.2016.05.162

[7] Traore, Y.B., Messan, A., Hannawi, K., Gerard, J., Prince, W. and Tsobnang, F. (2018) Effect of Oil Palm Shell Treatment on the Physical and Mechanical Properties of Lightweight Concrete. Construction and Building Materials, 161, 452-460. https://doi.org/10.1016/j.conbuildmat.2017.11.155

[8] Traore, Y.B., Messan, A., Hannawi, K. Gerard, J., Agbodjan, W. and Tsobnang, F. (2017) Experimental Investigations on the Physical and Mechanical Properties of a Lightweight Concrete Using Oil Palm Shell as Coarse Aggregate. Journal of Materials Science and Engineering A, 7, 157-168. https://doi.org/10.17265/2161-6213/2017.5-6.005

[9] Teo, D.C.L., Mannan, M.A. and Kurian, V.J. (2010) Durability of Lightweight OPS Concrete under Different Curing Conditions. Materials and Structures, 43, Article No. 1. https://doi.org/10.1617/s11527-008-9466-7

[10] Baroghel-Bouny, V., Chaussadent, T., Croquette, G., Divet, L., Gawsewitch, J., Godin, J., Henry, D., Platret, G. and Villain, G. (2002) Caractéristiques microstructurales et propriétés relatives à la durabilité des bétons (méthodes de mesure et d'essai de laboratoire), Techniques et Méthodes Des Laboratoires Des Ponts et Chaussées. Méthode.

[11] Spragg, R., Bu, Y., Snyder, K., Bentz, D. and Weiss, W. (2014) Electrical Testing of Cement-Based Materials: Role of Testing Techniques, Sample Conditioning, and Accelerated Curing. Joint Transportation Research Program, West Lafayette. https://doi.org/10.5703/1288284315230

[12] Balayssac, J.-P., Detriche, C.-H. and Grandet, J. (1993) Intérêt de l'essai d'absorption d'eau pour la caractérisation du béton d'enrobage. Materials and Structures, 26, 226-230. https://doi.org/10.1007/BF02472615

[13] Presuel-Moreno, F., Wu, Y.-Y. and Liu, Y. (2013) Effect of Curing Regime on Concrete Resistivity and Aging Factor over Time. Construction and Building Materials, 48, 874-882. https://doi.org/10.1016/j.conbuildmat.2013.07.094

[14] Cascudo, O., Pires, P. and Carasek, H. (2021) A. de Castro, A. Lopes, Evaluation of the Pore Solution of Concretes with Mineral Additions Subjected to 14 Years of Natural Carbonation. Cement and Concrete Composites, 115, Article No. 103858. https://doi.org/10.1016/j.cemconcomp.2020.103858

[15] Palod, R., Deo, S.V. and Ramtekkar, G.D. (2020) Effect on Mechanical Performance, Early Age Shrinkage and Electrical Resistivity of Ternary Blended Concrete Containing Blast Furnace Slag and Steel Slag. Materials Today: Proceedings, 32, 917-922. https://doi.org/10.1016/j.matpr.2020.04.747

[16] Real, S., Bogas, J.A. and Pontes, J. (2015) Chloride Migration in Structural Lightweight Aggregate Concrete Produced with Different Binders. Construction and Building Materials, 98, 425-436. https://doi.org/10.1016/j.conbuildmat.2015.08.080

[17] Benmerioul, F., Makani, A., Tafraoui, A. and Zaouai, S. (2017) Valorization of the Crushed Dune Sand in the Formulation of Self-Compacting-Concrete. Procedia Engineering, 171, 672-678. https://doi.org/10.1016/j.proeng.2017.01.408

[18] Pham, S.T. and Prince, W. (2014) Effects of Carbonation on the Microstructure of Cement Materials: Influence of Measuring Methods and of Types of Cement. International Journal of Concrete Structures and Materials, 8, 327-333. https://doi.org/10.1007/s40069-014-0079-y 